\title{
Impactos sociales de la transformación del espacio público (Ciudad de Buenos Aires, 2007-2017)
}

\section{Social impacts of the transformation of public space (City of Buenos Aires, 2007-2017)}

\author{
Juliana Marcús*
}

\section{Resumen}

Este artículo propone una reflexión en torno a las políticas públicas de planificación urbanística orientadas a la reconfiguración del espacio público en la Ciudad Autónoma de Buenos Aires llevadas a cabo desde 2007 y su impacto en la producción y la definición de nuevas reglas de uso de ese espacio.

Entendemos que la reestructuración del espacio público a partir de la implementación del Plan Movilidad Sustentable y de los procesos de renovación urbanística del área central de la Ciudad de Buenos Aires genera un nuevo orden urbano donde algunos usos de la ciudad se configuran como más legítimos que otros. Dichas políticas avanzan sobre lo urbano, sobre la espontaneidad y el dinamismo del espacio público e intentan regularlo, disciplinarlo y racionalizarlo. A esto se suma una política de planificación urbanística orientada a la valorización del suelo que responde a un modo de entender la ciudad como mercancía. ¿Qué tipo de ciudad se está produciendo? ¿Para quiénes? ¿Cuál es el rol del Estado y de los capitales privados en estos procesos? ¿Cómo y a partir de qué estrategias se piensa, planifica y gestiona la ciudad?

Palabras clave: Políticas urbanísticas, Espacio público, Impactos sociales, Transformación urbana, Ciudad de Buenos Aires.

\section{Abstract}

This article proposes a reflection on the public policies of urban planning oriented to the reconfiguration of public space in the City of Buenos Aires since 2007 and its impact on the production and definition of new rules of use of that space.

We understand that the restructuring of the public space from the implementation of the Sustainable Mobility Plan and the processes of urban regeneration of the Central Area of the City of Buenos Aires generates a new urban order where some uses of the city are configured as more legitimate

Fecha de recibo: 17 de septiembre de 2018 • Fecha de aceptación: 02 de octubre de 2018

\footnotetext{
* Doctora en Ciencias Sociales de la Universidad de Buenos Aires (UBA) y Licenciada en Sociología (UBA). Investigadora Adjunta del CONICET y del Instituto de Investigaciones Gino Germani. Miembro del Observatori d'Antropologia del Conflicte Urbá de Barcelona. Correo electrónico: julimarcus@gmail.com
} 
than others. These policies affect the urban, on the spontaneity and dynamism of the public space and try to regulate it, discipline it and rationalize it. Besides there is an urban planning policy oriented to valorization of urban land that understands the city as a commodity. What type of city is being produced? For whom it is? What is the role of the State and private capitals in these processes? How and from what strategies a city is thought, planned and managed?

Keywords: Urban policies, Public space, Social impacts, Urban transformation, City of Buenos Aires

\section{Introducción}

En las últimas tres décadas, la Ciudad Autónoma de Buenos Aires (CABA) ha sufrido un acelerado proceso de transformación socioespacial y reconfiguración urbana, al igual que otras metrópolis del mundo, en un contexto internacional de expansión del "urbanismo neoliberal" (Theodore, Peck y Brenner, 2009) que exige a las ciudades que funcionen como empresas orientadas hacia el rendimiento y la generación de ganancias, al tiempo que las convierte en una de las formas privilegiadas de absorción del capital excedente.

En este marco se desarrollan las dinámicas de producción y reestructuración del espacio público en la CABA analizadas en el presente trabajo. Nuestra hipótesis es que la implementación de políticas públicas de planificación y renovación urbanísticas $^{1}$ orientadas a la reconfiguración del espacio público en la ciudad capital para reconvertirlo en "espacio público de calidad" llevadas a cabo desde 2007 por la actual gestión del partido

De acuerdo con el antropólogo Jaume Franquesa (2007), consideramos que los proyectos de regeneración urbanística se presentan como estrategias de reestructuración del espacio que buscan crear oportunidades para la apropiación de plusvalía, es decir, que la obtención de grandes beneficios económicos es tanto la principal razón de la proliferación de estas reformas como la lógica que guía su desarrollo. político Propuesta Republicana (Pro), impacta en la producción y la definición de nuevas reglas de uso de ese espacio. Con la reestructuración del espacio público a partir de la implementación del Plan Movilidad Sustentable (Plan Prioridad Peatón, Red de Ciclovías y Bicisendas, Red de Metrobus, entre otros) y de los procesos de renovación urbanística del Área Central de la ciudad (Plan Microcentro, Casco Histórico, Plan Tribunales y Paseo del Bajo) se genera un nuevo orden urbano donde algunos usos de la ciudad se configuran y reglamentan como más legítimos que otros y se despliegan mecanismos de control sobre los usos permitidos y prohibidos de ese espacio urbano. Esta lógica del control y la regulación del espacio se observa, por ejemplo, en la política de "humanización del espacio público" llevada a cabo por el Gobierno de la ciudad (GCBA) y en la expulsión de los sujetos considerados "indeseables" ("cartoneros", "manteros", vendedores ambulantes, adultos que viven en la calle, entre otros) de la vía pública. ¿Qué tipo de ciudad se está produciendo? ¿Para quiénes? ¿Cuál es el rol del Estado y de los capitales privados en estos procesos? ¿Cómo y a partir de qué estrategias se piensa, planifica y gestiona la ciudad?

En la primera parte del artículo se exponen, por un lado, algunas consideraciones teóricas en torno a la producción social del espacio a partir de la tríada espacial propuesta por Henri Lefebvre (2013) [1974] como marco general dentro del cual entendemos las transformaciones del espacio público en la CABA, y, por otro lado, explicitamos el modo en que "la calle" deviene "espacio público" desde las retóricas urbanísticas y de las administraciones de gobierno a partir de las reflexiones del antropólogo Manuel Delgado Ruiz (2011). En la segunda parte analizamos los impactos sociales de la implementación del Plan Movilidad Sustentable haciendo hincapié en la construcción de la red de ciclovías, y los procesos de renovación urbanística del Área Central de la ciudad poniendo el foco en el Plan Microcentro como políticas públicas orientadas a la reconfiguración del espacio público tomando en cuenta 
los estudios colectivos (Marcús, 2018; Berardo y Vázquez, 2016-2017), realizados en el marco de dos proyectos de investigación financiados por la Universidad de Buenos Aires y el CONICET ${ }^{2}$. Por último, presentamos algunas reflexiones finales.

\section{La producción del espacio (público)}

De acuerdo con Henri Lefebvre (2013), el espacio es un producto social. Lejos de reducirse a receptáculo capaz de contener cuerpos y objetos, el espacio es el resultado de las acciones, prácticas y relaciones sociales, pero a su vez es parte de ellas. El espacio, entonces, debe considerarse un producto que se consume pero que interviene en su producción.

Para entender la producción social del espacio, Lefebvre propone una tríada conceptual compuesta por las prácticas espaciales, las representaciones del espacio y los espacios de representación. A cada una de estas dimensiones corresponde un tipo de espacio, respectivamente: el espacio percibido, el espacio concebido y el espacio vivido. La práctica espacial se relaciona con el espacio percibido, el más cercano a la vida cotidiana y a los usos de los lugares. En el contexto de una ciudad, la práctica espacial remite a lo que ocurre en las calles y en las plazas, los usos que éstas reciben por parte de habitantes e itinerantes, los diversos modos en que se apropian de los espacios y las formas en que el transeúnte recorre, circula y transita por la ciudad. Es el espacio de la experiencia material que vincula la realidad cotidiana con la realidad urbanística donde se suceden tanto la producción como la reproducción de la vida social. Es el uso imprevisto, espontáneo y astuto que hacen los caminantes y usuarios de la ciudad al (re)signi-

Nos referimos al Proyecto UBACyT 20020130200080BA (2014-2017) sobre el impacto de los procesos de mercantilización de la ciudad en los usos legítimos e ilegítimos del espacio urbano, y al Proyecto de Investigación Plurianual (PIP) CONICET 11220130100526CO (2014-2016) sobre producción social del espacio urbano, modos de habitar y modos de circular por la ciudad, dirigidos por la Dra. Juliana Marcús. ficar los espacios que se presentan organizados, planificados y estructurados. La dimensión de la representación del espacio se corresponde con el espacio concebido, el espacio provisto por el Estado, los científicos, los tecnócratas, los arquitectos, los planificadores y los urbanistas. "Es el espacio dominante en cualquier sociedad (o modo de producción)" (Lefebvre, 2013 p. 97), espacio de la fragmentación y la restricción. Es el lugar del orden y el poder, el espacio que prescribe y proscribe, que clasifica y regula. Por último, los espacios de representación son los espacios vividos, los que envuelven los espacios físicos y les sobreponen sistemas simbólicos complejos que lo codifican y los convierten en albergue de imágenes e imaginarios. En este espacio se inspiran las resistencias, deserciones y desobediencias ciudadanas y se cuestionan las reglas de la coherencia y la cohesión impuestas por las representaciones del espacio.

Según Lefebvre, existe una tensión y contradicción permanentes entre la representación del espacio, las prácticas espaciales y los espacios de representación. Se trata de comprender el espacio urbano como un espacio disputado entre diferentes actores sociales -Estado, desarrolladores urbanos, urbanistas, planificadores, organizaciones vecinales, usuarios e itinerantes urbanos- que pone en relieve el conflicto entre los usos del espacio señalados como legítimos y aquellos considerados ilegítimos, indebidos e incívicos. El espacio concebido, que se pretende abstracto e instrumental, busca regular y organizar los espacios percibido y vivido. En otras palabras, intenta disolver lo urbano, es decir las prácticas espontáneas y dispersas, y las experiencias propias de los habitantes de la ciudad para transformarlo en urbanización guiada por la lógica del conocimiento experto y del poder (Delgado, 2003).

Así, el espacio concebido hace efectiva la internalización de las estructuras del orden social entendido como orden urbano (Duhau y Giglia, 2004). Hablar de orden urbano supone partir del 
hecho de que los usuarios transitan y circulan por la ciudad a partir de conocimientos prácticos que indican los modos válidos y aceptados de uso de los diferentes espacios y artefactos urbanos. Ese orden urbano es incorporado por los usuarios bajo la forma de habitus urbano a partir de sus experiencias duraderas en el espacio social y en el espacio físico. Desde una perspectiva bourdieuna, los usuarios introyectan el sentido del juego urbano e incorporan las lógicas que regulan en un momento determinado la dinámica del espacio urbano en forma de "mapas mentales" (Bauman, 2005) que moldean sus percepciones y apreciaciones sobre la ciudad. El espacio urbano resulta así un espacio dinámico donde acontece la vida social, espontáneo y en permanente transformación.

Ahora bien, resulta imposible hablar de espacio urbano sin tener en cuenta la noción de espacio público. De acuerdo con los planteamientos de Delgado Ruiz (2011), el conflicto, las resistencias, las luchas y las negociaciones son características constitutivas de "la calle", el lugar de lo impredecible y lo azaroso, un espacio en el que constantemente se disputa la (re)definición de los usos en tanto legítimos e ilegítimos. Para el antropólogo catalán, el concepto de "espacio público" supone una categoría política e ideologizada a la que recurren arquitectos, urbanistas y administraciones gubernamentales para definir el "deber ser" de los exteriores urbanos -las calles, plazas y parques- no sólo mediante el diseño y la planificación del espacio, sino sobre todo a partir del disciplinamiento moral de sus habitantes y del despliegue de retóricas de civismo. El objetivo es garantizar la buena fluidez y regular las prácticas de los usuarios de la ciudad. En palabras de Delgado Ruiz,

"Se trata, pues, de disuadir y de persuadir cualquier disidencia, cualquier capacidad de contestación o resistencia y -también por extensión- cualquier apropiación considerada inapropiada de la calle o de la plaza, por la vía de la violencia si es preciso, pero previamente y sobre todo por una descalificación o una deshabilitación que ya no se lleva a cabo bajo la denominación de origen subversivo, sino de la mano de la mucho más sutil de incívico, o sea, contraventor de los principios abstractos de la "buena convivencia ciudadana" (Delgado, 2011, pp. 26-27).

Para el discurso urbanístico que rescata el "espacio público de calidad" su opuesto no es el espacio privado sino el espacio fusional: la propia impredecibilidad de "la calle", de lo urbano. La experiencia de la sociabilidad en el espacio público ideal es la de una concertación no fusional, es decir, basada en el distanciamiento y la reserva entre quienes la practican, mientras que la apropiación de "la calle" por los usuarios y las masas supone lo contrario: la negación provisional de las diferencias para conseguir una unidad que permita alcanzar un fin específico y circunstancial (Delgado, 2015). En tal sentido, el espacio público como ideología enmascara las relaciones sociales reales, es decir, conflictivas.

En este trabajo nos limitaremos a analizar, en primer lugar, el espacio urbano intervenido y modificado a partir de la construcción de las ciclovías en la CABA y la tensión que se produce entre su planificación llevada a cabo por el gobierno local y los modos en que ese espacio es percibido, usado, resignificado y apropiado por los habitantes de la ciudad. La proyección e implementación de la red de ciclovías como parte de las políticas públicas de transporte y movilidad urbana concebidas por el Estado y los planificadores se inscriben en las dinámicas de producción social del espacio e inciden tanto en la configuración y transformación de "la calle" en "espacio público de calidad" como en la regulación del espacio practicado por los habitantes. En segundo lugar, analizamos la renovación urbana del Área Central de la ciudad capital poniendo el foco en el Plan Microcentro como una política pública orientada a la reestructuración del espacio público y a la reconfiguración de sus usos. Para ello recuperamos los estudios realizados por Juliana Marcús (2018), y Martina Berardo y Diego Vázquez $(2016,2017)$. 


\section{Los impactos sociales de la reestructuración del espacio público}

\section{La red de ciclovías: tensiones entre los espacios concebidos y las prácticas espaciales}

En esta primera sección del segundo apartado pondremos el foco en la implementación de las ciclovías y su impacto en la práctica de ese espacio teniendo en cuenta las tensiones y contradicciones entre los usos previstos e imaginados y los usos reales y concretos. De modo que el análisis estará centrado en la distancia y las tensiones entre el diseño y la implementación de la política pública de ciclovías en el marco de la estructuración de espacios concebidos por el Estado y los planificadores urbanos y lo que efectivamente sucede a partir de su construcción, es decir, las modificaciones en el denominado "espacio público" y la práctica espacial. ${ }^{3}$

La red de ciclovías de la ciudad comenzó a construirse en las calles y avenidas porteñas en julio de 2009 y actualmente alcanza los $205 \mathrm{~km}$. (Niebla, 2018). Se trata de carriles de doble circulación exclusivos para bicicletas, resguardados del resto del tránsito vehicular por medio de un separador físico. Según el GCBA "la red fue especialmente diseñada para fomentar el uso de la bicicleta y para integrar distintos puntos estratégicos de la ciudad como centros de transbordo, universidades, escuelas y hospitales permitiendo también la interconexión con otros medios de transporte" (Buenos Aires Ciudad, s.f.). Actualmente la

Nuestro interés radica en indagar por un lado, el impacto que ha generado la construcción de sendas exclusivas para la circulación de bicicletas en la transformación del espacio urbano y, por el otro, en el modo en que estas vías son percibidas, usadas y reapropiadas por habitantes, viandantes y peatones. En esta oportunidad, no nos detendremos en la práctica espacial que los usuarios de bicicletas hacen de las ciclovías puesto que excede la preocupación y reflexión teórica que procuramos abordar en este trabajo. ciudad dispone de 200 estaciones automáticas de "Ecobici", el sistema gratuito de transporte público de bicicletas.

La política de ciclovías se enmarca dentro del "Plan Movilidad Sustentable" del GCBA que consiste en el rediseño de "la calle" en "espacio público de calidad" para fomentar el ordenamiento, la seguridad vial y la "movilidad saludable" a través de entornos de interacción adecuados para dichos fines. Según los funcionarios del gobierno entrevistados, "el objetivo es incentivar la movilidad peatonal con políticas de peatonalización de ciertas zonas de la ciudad, estimular el uso de las bicicletas a partir de la construcción de una red de ciclovías y dar prioridad al transporte público mediante la construcción del metrobus ${ }^{4 \prime}$.

Este paradigma urbanístico contemporáneo basado en la "ciudad sustentable" tiene en las intervenciones del arquitecto danés Jan Gehl su expresión más acabada. Sus trabajos sobre el rediseño de la ciudad de Copenhague hicieron de ésta uno de los entornos más favorables para ciclistas y peatones convirtiéndola en un ícono mundial en cuestiones de movilidad sustentable y planificación urbana. Su modelo urbanístico tendiente a desarrollar y promover "ciudades para la gente" (Gehl, 2014) a partir de la "humanización del espacio urbano" (Gehl, 2006) ha sido elegido por el GCBA $^{5}$ para alcanzar los objetivos de planificación urbanística orientados a concretar una Ciudad de Buenos Aires sustentable en la que se

\footnotetext{
4 Sendas exclusivas para la circulación de autobuses.

5 De hecho, el GCBA auspició en 2016 una clase magistral dictada en la Ciudad de Buenos Aires por el Gehl Architects titulada "Ciudades para la gente: herramientas para el cambio". Además, contrató al estudio de arquitectura para tareas de consultoría sobre la planificación estratégica para urbanizar la zona portuaria de Retiro y una calle comercial en la Villa 31, iniciativa que generó polémica en la Sociedad Central de Arquitectos que manifestó su disconformidad al argumentar que "el diseño de un plan estratégico de una ciudad le corresponde hacerlo al Estado. Para ello debería armar un equipo especializado (...) Es un agravio para los profesionales que ningún estudio de arquitectura local participe de esta iniciativa" (Corsalini, 2017).
} 
priorice sobre todo la circulación peatonal y de bicicletas para el encuentro de las personas en el espacio público en detrimento de los espacios para la circulación de automóviles. Este urbanismo que podemos denominar contemporáneo es crítico de los lineamientos básicos de la corriente moderna o funcionalista, aquella que postulaba como criterios generales la escisión de las cuatro funciones básicas que identificaba en los ciudadanos -habitar, trabajar, circular y recrearse- y una estricta separación de estas actividades en el espacio a través de la planificación a gran escala y la prioridad al transporte motorizado. Estas ideas, desarrolladas en los Congresos Internacionales de Arquitectura Moderna de finales de la década del '20, sintetizadas en la "Carta de Atenas" de 1930 y cuyo máximo exponente mundial fue Le Corbusier, hegemonizaron el urbanismo internacional durante buena parte del siglo XX.

Según el GCBA, las ciclovías "son construidas estratégicamente en calles secundarias procurando evitar aquellas de alto tránsito vehicular", aunque a partir de las observaciones realizadas en un barrio céntrico de CABA analizadas en un trabajo anterior (Marcús, 2018) hemos constatado que no es así: muchas de las ciclovías se encuentran construidas sobre calles por las cuales circulan líneas de autobuses y camiones lo que produce atascos frecuentes en el tránsito y un incremento del ruido causado por las insistentes bocinas de automóviles particulares, taxis y autobuses producto de estos embotellamientos. Asimismo hemos observado que ni bien aparecieron las ciclovías en las zonas céntricas de la ciudad, las mismas se encontraban ausentes de bicicletas cuando justamente habían sido especialmente diseñadas para su circulación. Esos carriles vacíos de bicicletas comenzaron a llenarse de otros usos posibles, espontáneos y (re)creativos. Observamos que los vecinos y usuarios de la ciudad los utilizaban para pasear a sus perros, practicar footing, andar en rollers o skaters, estacionar sus automóviles, circular en moto o ubicar los contenedores de basura. Estas prácticas espaciales pueden ser consideradas tácticas

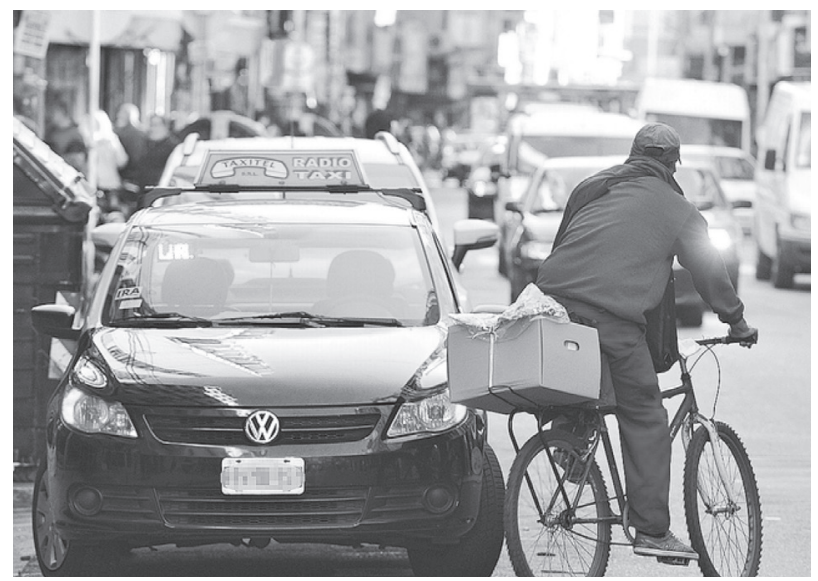

Figura 1. Usos imprevistos de las ciclovías en la Ciudad de Buenos Aires. Fuente: Diario Clarín, 2014

(De Certeau, 2000) que ponen en tensión el uso previsto de esta senda diseñada para la circulación exclusiva de bicicletas. Para De Certeau existe la posibilidad de que el espacio estructurado por el poder, es decir, el lugar de la estrategia, sea alterado a través de las prácticas cotidianas de los practicantes ordinarios de la ciudad, desplegando tácticas en un terreno ajeno. En los desvíos, en las mil maneras de hacer, el habitante de la ciudad imprime nuevos sentidos y se reapropia del espacio, desestructurándolo y reestructurándolo permanentemente. Mediante astucias furtivas los usuarios del espacio tienen la capacidad de abrir un espacio original y de creación. En este sentido, el espacio urbano, la "calle", es siempre un lugar practicado por transeúntes que se apropian y subvierten a través de sus tácticas espaciales el orden estratégico impuesto por el urbanismo.

De modo que pareciera que un espacio público planificado, o concebido por urbanistas y técnicos del gobierno, no previera el impacto que produce esa planificación en la transformación barrial en tanto paisaje urbano y en tanto uso y apropiación de ese espacio. De hecho, el esquema producido sobre el papel planifica ciertos usos, en este caso la circulación de bicicletas, sin contemplar los usos imprevistos y espontáneos. Así, el espacio público diseñado se piensa como un texto que vehiculiza un único discurso simplificando la complejidad y 
la multiplicidad del espacio urbano real, es decir, "la calle". La pretensión del espacio concebido es, entonces, dotar de coherencia ese espacio real y caótico pero desde su proyección. Desde esta lógica hay un intento permanente por normalizar y disciplinar el uso del espacio urbano, por regular lo imprevisible y lo azaroso, por ordenar "la calle" para convertirla en "espacio público de calidad". Es el espacio público "concebido y reconocido como propiedad privada de un poder político centralizado (...) que se ha autoarrogado la función de fiscalizarlo e imponerle sus sentidos" (Delgado Ruiz, 2004, p. 12). Sin embargo, difícilmente los espacios de representación y las prácticas espaciales se sometan plenamente a las reglas de coherencia que se pretenden imponer desde la representación de los espacios ya que, tal como manifiesta Lefebvre (2013), es imposible inmovilizar completamente lo urbano. Se trata de una distancia entre el espacio público diseñado y el espacio urbano real donde acontecen innumerables y heterogéneas acciones sociales. ${ }^{6}$

\section{La humanización del espacio: transformaciones urbanas en el microcentro porteño}

Junto con el desarrollo de la red de ciclovías, el GCBA ha implementado el Programa Prioridad Peatón que consistió en la peatonalización de ciertas áreas de la ciudad como el Microcentro porteño, Tribunales y un sector del barrio de San

\footnotetext{
6 Meses después de la implementación de las ciclovías, los usos tácticos de esas sendas, sobre todo los lúdicos como pasear al perro o practicar footing, comenzaron a convivir con la incipiente circulación de bicicletas. De a poco algunos usos alternativos, como la circulación de motos, los automóviles estacionados y la irrupción de los contenedores de basura, se volvieron condenables por los ciclistas que consolidaron su presencia en la escena vial por considerarlos peligrosos y causantes de accidentes al entorpecer la circulación de bicicletas. Paulatinamente el nuevo orden espacial fue interiorizado tanto por los transeúntes y los residentes del barrio como por los ciclistas que comenzaron a desplazarse por esos carriles justamente pensados desde la planificación para la circulación de bicicletas.
}

Telmo. ${ }^{7}$ En este trabajo nos centraremos en el Plan Microcentro y sus impactos sociales.

El Plan Microcentro, implementado en las gestiones 2007-2015 del Pro en la CABA, implicó notables modificaciones del paisaje urbano así como la prescripción de nuevos usos legítimos e ilegítimos del espacio. El Microcentro constituye una parte neurálgica de la CABA, un sector estratégico que combina múltiples usos: políticos, financieros, comerciales, religiosos y turísticos. Podemos considerarla una zona central de la CABA puesto que en ella nacen casi todas las líneas de subterráneo y tres de las grandes líneas de trenes que conectan el Conurbano Bonaerense y el interior del país con la ciudad tienen la estación central a sus puertas. Sin embargo, a pesar de ser una zona muy transitada en los horarios diurnos, carece casi de población estable debido a que gran parte de sus edificios son utilizados como oficinas (Berardo y Vázquez, 2016).

Las atracciones históricas y culturales que presenta el Microcentro porteño lo convierten en un polo turístico promovido fuertemente por el GCBA. A su vez, el centro financiero opera como el motor que moviliza la adquisición de un conjunto de artefactos urbanos modulados y configurados por los requerimientos de la globalización, con el fin de atraer actividades y empresas transnacionales. Como afirma David Harvey (2013), lo que se intenta desde las lógicas gubernamentales es seducir flujos de capital a través de las "marcas especiales de distinción" que constituyen un capital simbólico colectivo capaz de atraer al turismo internacional y a las grandes empresas. De esta forma, el capital simbólico adherido a la marca Buenos Aires (Marcús, 2014) otorga grandes ventajas económicas a partir de la posibilidad de obtener una renta monopólica que se produce por la explotación de la singularidad de este espacio. Dentro de esta lógica de neoliberalización del espacio (Franquesa, 2007) se inició la regeneración

Para 2019 está proyectado que las vías peatonales se extiendan hacia Retiro y Once. 


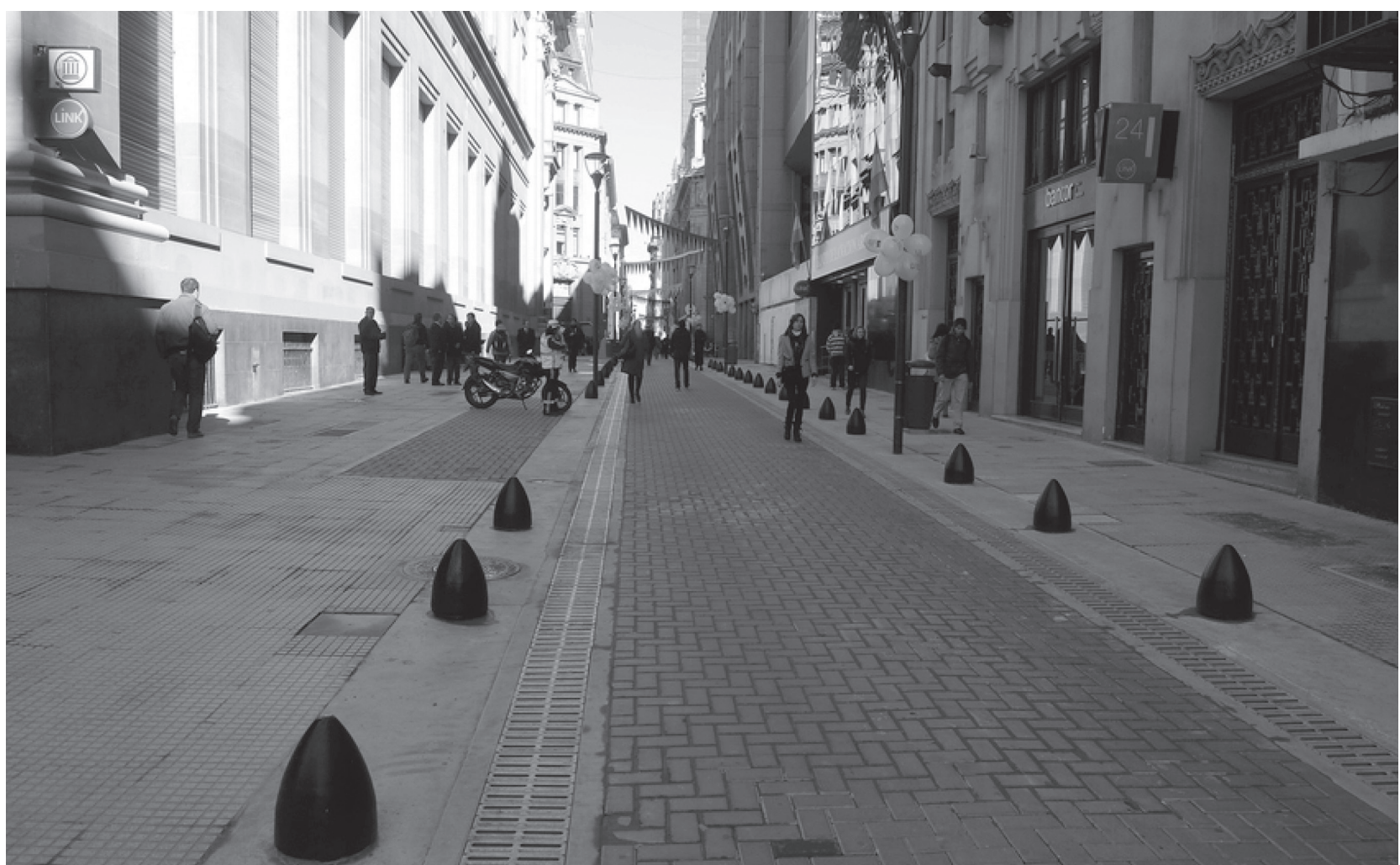

Figura 2. Peatonalización del microcentro porteño. Fuente: Diario Clarín, 2013

urbanística que buscó reestructurar el espacio público del Microcentro.

Las principales obras que contempló el Plan Microcentro fueron: 1) la renovación de las avenidas y peatonales (modificación de veredas, luminarias led, colocación de canteros y árboles, reordenamiento de puestos de diarios y eliminación de cartelería fuera de norma) lo que supuso una homogeneización del paisaje urbano de la zona; 2) la restauración de los edificios patrimoniales; 3) el aumento de presencia policial en la zona; 4) y el establecimiento de áreas peatonales con el ensanchamiento de veredas, su nivelación a la calle y el ordenamiento del tránsito ${ }^{8}$. La peatonalización de las áreas centrales es una tendencia notoria en grandes ciudades como Nueva York, Madrid,

$8 \quad$ Este aspecto incluyó la reorganización del sentido del tránsito en avenidas, el establecimiento de dársenas y horarios para carga y descarga de bienes, el impedimento de la circulación de transporte público y la restricción de velocidad para vehículos y motocicletas particulares.
México, Pekín, París y Moscú (Redacción El País, 2016). En este sentido, es posible identificar en este plan de reformas una intención de dotar a la ciudad de un conjunto de características de manera tal de estandarizar aspectos de la ciudad con la finalidad de volverla similar a otras y, de esta manera, poder competir en el mercado internacional de ciudades por la atracción de los capitales trasnacionales y el turismo internacional. El intento por volver comercializable a la Ciudad de Buenos Aires se hace posible a través de la estandarización de bienes y servicios. Se trata de posicionarse como una ciudad que se presenta dotada de los servicios necesarios para el desarrollo de la actividad económica de las empresas transnacionales que decidan localizarse allí.

A partir del trabajo de observación realizado por Berardo y Vazquez $(2016,2017)$, es posible considerar que estas medidas fueron planificadas no sólo con el propósito de generar más espacios para transitar y darle protagonismo al sujeto, sino, y 
sobre todo, para reconvertir la "calle", conflictiva por definición, en "espacio público de calidad", pasible de ser vendido en el mercado como un espacio armonioso que invite al sujeto a "pasear" por un espacio que en el imaginario colectivo supone una zona caótica. Pero la "invitación" no es a cualquier sujeto, sino al sujeto-peatón y al sujetoturista, es decir, aquel que utiliza la calle como pasaje hacia otro lugar o aquel que la contempla como "vidriera" a ser consumida. De esta forma, la política de renovación del Microcentro basada en la "humanización del espacio" apunta a reconvertir ese espacio para la mera circulación peatonal y contemplación turística y no para la apropiación y la permanencia de los sujetos en ese espacio. Entonces, ¿qué supone humanizar el espacio? Como veremos más adelante, no todo usuario será bienvenido $^{9}$ ni merecerá circular, y menos aún permanecer, en ese espacio público reconfigurado.

Tal como desarrollamos en párrafos anteriores, el GCBA ha seguido los planteos de la planificación estratégica fundada en las ideas de Jan Gehl para reconfigurar el Microcentro porteño cuyos lineamientos proponen crear ciudades a "escala humana" al tiempo que critica la pérdida del "lugar tradicional que ocupaba el espacio urbano como foro social para los habitantes de las ciudades" (Gehl, 2014, p. 6). A su vez, subraya la necesidad de "reforzar la función social del espacio público como un lugar de encuentro, una herramienta vital en pos de lograr una sociedad sostenible y una comunidad abierta y democrática" (Ibídem).

Cuando comenzó a llevarse adelante el Plan Microcentro, el entonces Jefe de Gobierno porteño, Mauricio Macri, expresó que en el espacio público "se genera el encuentro y la relación entre las personas, en él se expresan las individualidades y el espíritu colectivo y en él se construye la identidad

Recordemos que en 2011 la campaña política por la reelección de Mauricio Macri como Jefe de Gobierno de la Ciudad de Buenos Aires, presentó el sugerente slogan "Vos sos bienvenido" a la ciudad como si se tratara de un espacio privado en el que el dueño se reserva el derecho de admisión. Para profundizar en este tema, véase Marcús, 2014.

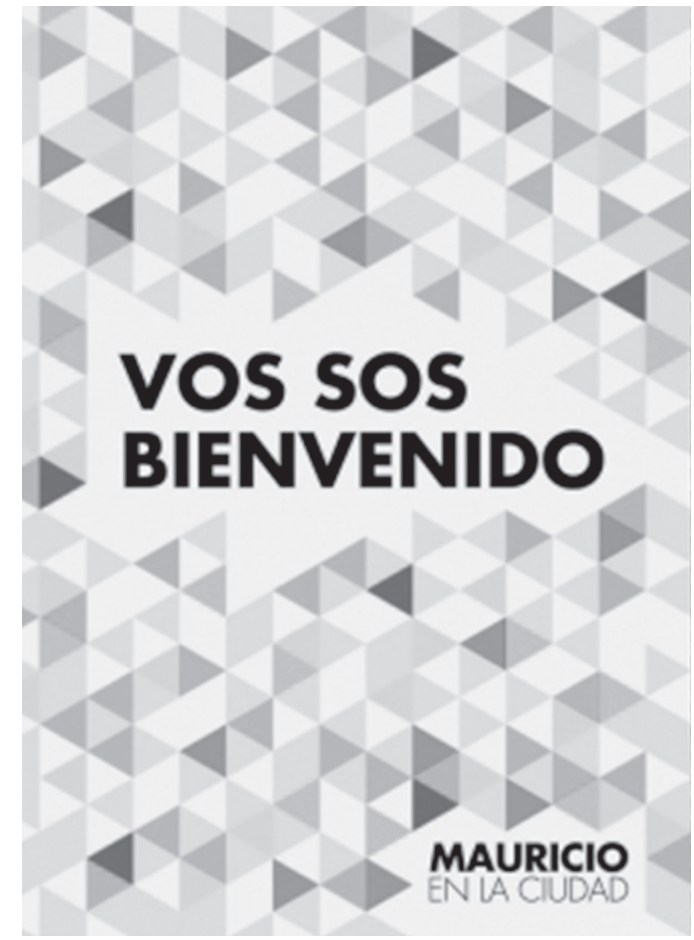

Figura 3. Slogan de la campaña política de 2011 por la reelección de Mauricio Macri en la Ciudad de Buenos Aires. Fuente: Archivo electoral, 2011

ciudadana"(Buenos Aires Ciudad, 2009; Berardo y Vázquez, 2017, p. 177). Este tipo de discursos, compartido por otros funcionarios del GCBA, recupera las retóricas del urbanismo contemporáneo y comprende al espacio público como "un proscenio amable y desconflictivizado en que se territorializan los principios abstractos de la mediación estatal y en el que los segmentos enfrentados de la sociedad pactan una tregua perpetua y aceptan dirimir aparte, 'en otro sitio', sus contenciosos" (Delgado, 2013, p. 55). Esta concepción idílica e ideológica identifica al espacio público como el lugar donde se ejercen los derechos de expresión y reunión de un ciudadano abstracto propio de la concepción del liberalismo político.

En este sentido, el espacio público opera como una herramienta de armonización en una idea de sociedad civil en donde el pacifismo, la tolerancia y el consenso son valores deseables que se presentan como la contracara de los contrastes entre las clases sociales. El conflicto es entonces exhibido 
como indeseable y la intención manifiesta de los proyectos urbanísticos y sociales es eliminarlo. En otras palabras, la noción misma del espacio público que elaboran excluye expresamente toda hipótesis de conflicto entre los sujetos y usuarios de la ciudad.

Por lo tanto, los proyectos del urbanismo neoliberal que remarcan la necesidad de intervenir el espacio urbano para conseguir "espacios públicos de calidad" están orientados a producir espacios para las "buenas prácticas urbanas" en donde pueda desarrollarse la utopía liberal de "una sociedad culta, amable y limpia (...) y [de donde] son expulsados o excluidos todos aquellos que hayan sido declarados indeseables, aunque sólo sea por su incapacidad de exhibir modales de clase media" (Delgado, 2013, p. 57). En sintonía con esta sentencia, un asesor del GCBA relataba el modo en que se encaró el desafío de convertir la "calle" en "espacio público de calidad" en el Plan del Microcentro:

"[hemos respondido] a los problemas de la ciudad con acciones tendientes a neutralizar a ciertos humanos desaprensivos -que por cierto son muchos- y sus aspiraciones personales sobre el bien común [...] En estos términos, humanizar es generar acciones para estar en sintonía con los usos y costumbres de la especie y la comunidad que la alberga, proponiendo soluciones a lo inmediato y -ipor supuesto!-, paralelamente políticas que construyan lo mediato: prevención, educación y punición" (Buenos Aires Ciudad, 2009).

La concepción del espacio público construida por el Pro, antes que una enunciación sobre el "espacio público real", constituye una expresión de deseo, un "deber ser" del espacio público. Su definición como lugar vital de las ciudades que deben promover el encuentro, la reunión y la buena convivencia entre los diferentes actores de la sociedad deriva en la urgencia de humanizarlo (Berardo y Vázquez, 2017).

Desde su planificación, el Plan Microcentro se propuso reorganizar los usos del espacio público a través de una nueva regulación y de intervenciones materiales que promovieron determinadas actividades y restringieron otras. El paradigma de la "humanización del espacio público" parte de considerar que las modificaciones materiales en el espacio urbano producen efectos sociales, es decir, modificaciones en los usos y comportamientos de los usuarios y habitantes (Berardo y Vázquez, 2017). El fuerte carácter regulador del proyecto tenía como intención ordenar un paisaje que se presentaba como caótico a través de la sanción de normativas explícitas que establecían qué podía permanecer en el espacio, cómo debía hacerlo y qué debía ser eliminado. En este sentido, la concepción del Pro del espacio público como lugar de encuentro democrático de la diversidad de la sociedad encontró su primer límite. Dentro de la reorganización de la zona se incluyeron operativos ejecutados por fuerzas policiales para desalojar a los denominados "manteros"10 que trabajaban sobre la peatonal Florida ${ }^{11}$. A su vez, se ordenó la persecución y el hostigamiento nocturno hacia las personas que viven en la calle.

Este accionar del GCBA a través de las fuerzas de seguridad constituye un claro ejemplo de la neutralización de los sujetos considerados "incívicos" e "indeseables", uno de los elementos de la política de humanización del espacio público del Pro. Desde su óptica, los vendedores ambulantes y las personas que viven en la calle realizan usos desaprensivos del espacio público. Ante la imposibilidad de "disciplinarlos" y "domesticarlos", se optó por su expulsión de la calle. Detrás de la narrativa que mostraba al espacio público como espacio de convivencia democrática, se ocultó la existencia de relaciones sociales desiguales y del orden social

10 Vendedores de mercancías de consumo popular en la vía pública.

11 Estos operativos fueron realizados entre 2007 y 2017 en diferentes puntos comerciales de la ciudad: Microcentro, Once y Flores. Luego, algunos de estos vendedores fueron relocalizados en predios cerrados y alejados de las zonas comerciales en las que originalmente realizaban su trabajo, y consecuentemente invisibilizados. Para profundizar en este tema, véase Peralta, 2017. 
que se impone con violencia sobre los excluidos del espacio público. Esto nos recuerda los postulados y advertencias de la sociología urbana francesa que, al igual que el urbanismo contemporáneo, también rescataba al espacio público frente a los postulados funcionalistas, pero ya no como el lugar armónico del civismo, sino como el espacio de lo urbano, un espacio que supone la simultaneidad, los encuentros, la convergencia y el reconocimiento, pero también las confrontaciones de las diferencias, los conflictos y los enfrentamientos (Martínez Lorea, 2013).

\section{Palabras finales}

A partir de dos casos de estudio, la construcción de la red de ciclovías y la renovación del Microcentro porteño, hemos analizado los impactos sociales que suponen las transformaciones del espacio público. En el primer caso hemos considerado la relación entre el diseño del espacio público y los usos reales y concretos que desestructuran y reestructuran constantemente ese espacio planificado y estructurado (Marcús, 2018). En el segundo caso analizamos las retóricas y políticas urbanísticas de "humanización del espacio" que configuran un "espacio público de calidad" en el que no todos los sujetos resultan bienvenidos. Este espacio es presentado como el espacio democrático por antonomasia, desconflictivizado, "la esfera de coexistencia pacífica y armoniosa de lo heterogéneo de la sociedad, marco en que se supone que se conforma y se confirma la posibilidad de estar juntos" (Delgado y Malet, s/f, p. 58). A partir del análisis realizado por Berardo y Vazquez (2016, 2017) concluimos que la retórica de la renovación del Área Central de la ciudad fundada en la belleza y la estetización donde algunos usos se reglamentan como más legítimos que otros, se presenta como una estrategia para el desarrollo económico de la zona para atraer inversiones económicas y turismo. Estas retóricas valoran el espacio público como un espacio para la mera circulación, como forma estática para ser usado como lugar de paso (Peralta, 2017) al que se le niegan ciertas formas de apropiación consideradas "incívicas e insolentes"12 y que afectan a la convivencia "armónica". Así, la defensa del espacio público como el "espacio del civismo" opera como "narrativa legitimadora" (Franquesa, 2007), es decir, se condenan los usos percibidos como "ilegítimos" y se despliegan retóricas que resultan estigmatizantes hacia los sujetos considerados "indeseables" reforzando y apuntalando los procesos de renovación del espacio público.

Estos modos hegemónicos de producción de espacio urbano ligados a la ciudad-mercancía inciden en el incremento del precio del suelo urbano, en el acceso diferencial al territorio, en la expulsión de los habitantes de sus barrios y en la mercantilización de las relaciones urbanas. De esta forma, se configura una Ciudad Autónoma de Buenos Aires en la que se profundizan las diferencias de clase e injusticias sociales y se refuerza la concepción de una ciudad jerarquizada reservada a los sectores medios y altos de la sociedad.

Pero además, las políticas públicas urbanas y culturales orientadas a procesos de renovación urbanística que promueven la puesta en valor del patrimonio urbano y fortalecen la marca Buenos Aires para atraer al turismo y las inversiones de capitales privados, sumado a las escasas políticas habitacionales hacia los sectores populares para garantizarles el derecho a una vivienda digna y a los mecanismos de control y regulación del espacio público porteño, por mencionar sólo algunas de las políticas de la última década, contribuyen a la (re)producción material de una ciudad que se vuelve cada vez más desigual social, económica y territorialmente (Marcús, 2017). Una ciudad que reactualiza las fronteras simbólicas de permisividad

\footnotetext{
12 Nos referimos a prácticas del espacio realizadas por los llamados "manteros", "cartoneros", "trapitos", vendedores ambulantes, trabajadoras sexuales en la vía pública, adultos que viven en la calle, entre otros sujetos considerados "indeseables" desde las retóricas urbanísticas, las administraciones de gobierno, algunos medios de comunicación, cámaras empresariales y algunos movimientos de vecinos organizados autodenominados "buenos vecinos".
} 
y exclusión al definir quiénes merecen habitarla y quiénes no (Oszlak, 1991). Para ello activa diversos mecanismos de vigilancia y expulsión hacia los considerados indeseables que luchan cotidianamente por acceder y permanecer en la ciudad.

El urbanismo contemporáneo dentro del cual se pueden considerar las políticas urbanísticas desplegadas desde la gestión del Pro en la CABA, escondido tras la retórica de la defensa del "espacio público de calidad”, amenaza al espacio urbano y le exige la adaptación de los usos a la forma y a la norma impuesta. El objetivo del urbanismo es siempre imponer su orden urbano. En este sentido, las políticas urbanísticas analizadas en este trabajo avanzan sobre lo urbano, sobre la espontaneidad y el dinamismo de "la calle", devenida "espacio público" desde las retóricas urbanísticas y de las administraciones de gobierno, e intentan regularla, disciplinarla y racionalizarla. A esto se suma una política de planificación urbanística orientada a la valorización del suelo que responde a un modo de entender la ciudad como mercancía.

\section{Referencias bibliográficas}

Archivo electoral (2011). Vos sos bienvenido. Recuperado de: goo.gl/zgGKYb

Bauman, Z. (2005). Modernidad Líquida. Buenos Aires: Fondo de Cultura Económica.

Berardo, M. y Vázquez, D. (2016). La producción del espacio PRO: Contradicciones urbanas en torno a la reforma del Microcentro porteño (2007-2015). IX Jornadas de Sociología de la UNLP, La Plata.

Berardo, M. y Vázquez, D. (2017). ¿La humanización del espacio? La PRO-ducción de espacio público en el Microcentro porteño (2007-2015). En Marcús, J. (Coord.) Ciudad Viva. Disputas por la producción sociocultural del espacio urbano en la Ciudad de Buenos Aires. Buenos Aires: Editorial Teseo, pp. 169-206.

Buenos Aires Ciudad (s.f.). "Pedaleá la Ciudad. Conocé los carriles exclusivos para bicicletas".
Recuperado el 20/04/18 de: http://www.buenosaires.gob.ar/ecobici/pedalea-la-ciudad

Buenos Aires Ciudad (2009). La humanización del espacio público. Buenos Aires: Ministerio de Desarrollo Urbano, Gobierno de la Ciudad. Recuperado de: http://cdn2.buenosaires.gob.ar/ desarrollourbano/publicaciones/la-humanizacion-del-espacio-publico-2009.pdf

Corsalini, C. (23/04/2017). Adjudican un megaplan para la ciudad a un estudio danés y estalló la polémica. Perfil. Recuperado de: https://goo. $\mathrm{gl} / 64 \mathrm{q} 01 \mathrm{C}$

Delgado Ruiz, M. (2003). La no-ciudad como ciudad absoluta. Sileno, (13), pp. 123-131.

Delgado Ruiz, M. (2004). De la ciudad concebida a la ciudad practicada. Archipiélago. Cuadernos de crítica de la cultura, n 64, pp. 7-12.

Delgado Ruiz, M. (2011). El espacio público como ideología. Madrid: Catarata.

Delgado Ruiz, M. (2013). Espacio público: discurso y acción. El papel de la calle en las movilizaciones sociales a principios del siglo XXI. Revista Zainak (36), pp. 37-60.

Delgado Ruiz, M. (2015). La redención de las multitudes: rescate y restauración del sujeto en los movimientos sociales de última generación. En: Intersticios. Revista Sociológica de Pensamiento Crítico. Vol 9, No 2, pp. 101-129.

Delgado Ruiz, M. y Malet, D. (s/f). El espacio público como ideología. UrbanDoc. 1, 57-65. Recuperado de: http://www.fepsu.es/docs/urbandocs/UR BANDOC1.pdf

Duhau, E. y Giglia, A. (2004). Conflictos por el espacio y orden urbano. Estudios demográficos y Urbanos, (56), pp. 257-288.

Duhau, E. y Giglia, A. (2008). Las reglas del desorden: habitar la metrópoli. Ciudad de México: Siglo XXI.

Franquesa, J. (2007). Vaciar y llenar, o la lógica espacial de la neoliberalización. Revista Española de Investigaciones Sociológicas, Núm. 118, pp. 123-150. 
Gehl, J. (2006). La humanización del espacio urbano: la vida social entre los edificios. Barcelona: Reverté.

Gehl, J. (2014). Ciudades para la gente. Buenos Aires: Infinito.

Harvey, D. (2013). Ciudades Rebeldes. Madrid: Akal.

Lefebvre, H. (2013) [1974]. La producción del espacio. España: Capitán Swing.

Niebla, K. (29/04/2018). Ecobici tiene récord de viajes pero crecen las quejas por el mal estado de las bicicletas. Diario Clarín. Recuperado de: https://goo.gl/Ae2EZ7

Marcús, J. (2014). 'Vos (no) sos bienvenido'. El control y la regulación del espacio urbano en la Ciudad de Buenos Aires, Scripta Nova, XVIII, núm. 493 (15), pp. 1-17.

Marcús, J. (2017). Introducción. La ciudad en disputa. En: Marcús, J. (Coord.) Ciudad Viva. Disputas por la producción sociocultural del espacio urbano en la Ciudad de Buenos Aires. Buenos Aires: Editorial Teseo, pp. 17-32.

Marcús, J. (2018). Las ciclovías en la Ciudad de Buenos Aires y su impacto en las transformaciones urbanas, sociales y culturales. En Marcelo Urresti (coord.), Viajeros, peatones y conductores. Una sociología de la movilidad y el transporte en la Ciudad de Buenos Aires. Buenos Aires: Editorial Teseo. En prensa.

Martínez Lorea, I. (2013). Henri Lefebvre y los espacios de lo posible. En H. Lefebvre, La producción del espacio (pp. 7-28) España: Capitán Swing.

Oszlak, O. (1991). Merecer la Ciudad: los pobres y el derecho al espacio urbano. Buenos Aires: CEDES/Hvmanitas.

Peralta, M.A. (2017). Un "otro" en el centro de la ciudad. Los "manteros" y el conflicto en torno a los usos de la vía pública. En: Marcús, J. (Coord.) Ciudad Viva. Disputas por la producción sociocultural del espacio urbano en la Ciudad de Buenos Aires. Buenos Aires: Editorial Teseo, pp. 131-168.

Redacción Clarín (15/06/2014). Tránsito y transporte. Ciclovías cada vez más usadas pero invadidas por obstáculos. Diarío Clarín. Recuperado de: goo.gl/9kA7Bu

Redacción Clarín (2013). Peatonalización del microcentro porteño. Diario Clarín. Recuperado de: goo.gl/t1QXUg

Redacción El País (18/12/2016). Las grandes urbes del mundo apuestan por la peatonalización Diario El país. Recuperado de: goo.gl/uDZ4V8

Theodore, N.; Peck, J. y Brenner, N. (2009). Urbanismo neoliberal: la ciudad y el imperio de los mercados. Revista Temas Sociales, (66), pp. 1-11. 